\title{
Index Design and System Analysis of Engineering Education Accreditation Evaluation System
}

\author{
Yan Changshun, Shao Yong* \\ Faculty of Information Technology, Beijing University of Technology, Beijing, China \\ Email address: \\ yuewuxing@bjut.edu.cn (Yan Changshun), mazel@bjut.edu.cn (Shao Yong) \\ ${ }^{*}$ Corresponding author
}

To cite this article:

Yan Changshun, Shao Yong. Index Design and System Analysis of Engineering Education Accreditation Evaluation System. Science Journal of Education. Vol. 9, No. 3, 2021, pp. 110-114. doi: 10.11648/j.sjedu.20210903.16

Received: April 19, 2021; Accepted: June 2, 2021; Published: June 4, 2021

\begin{abstract}
The connotation of professional certification of engineering education is that a professional certification evaluation organization conducts a comprehensive evaluation of engineering professional disciplines set up by educational institutions. The entire evaluation process consists of specialized occupations, industry associations, industry federations, professional societies and education in this field. Experts and enterprise experts in related industries work together to ensure that these engineering professionals have sufficient professional qualities and abilities when entering the real industrial social environment. At present, the whole process of engineering education professional certification in China mainly relies on manual audit applications. In order to realize the interconnection between applicants and evaluators, an engineering education professional certification and evaluation system is needed. Through this platform, the docking between universities and evaluation expert groups can be realized, and the evaluation results can be visualized. This paper is a part of the basic work of the evaluation system. Its main work is: using data analysis and expert method to analyze the general standard of engineering education professional certification; By using data analysis and expert method, this paper analyzes some relevant standards of Engineering Education Accreditation in China; The specific indicators of the engineering education accreditation evaluation system are screened out by using the expert method; According to the whole process of evaluation and certification, combined with the characteristics of other evaluation systems, the index system of evaluation system is designed; Completed the functional and non functional analysis of the evaluation system. These works lay a solid foundation for the design and implementation of the subsequent engineering education accreditation evaluation system.
\end{abstract}

Keywords: Engineering Education Professional Certification, Evaluation Index, System Analysis

\section{Introduction}

At the beginning, the development of China's engineering education accreditation process is relatively slow, and the overall layout and system are still in the exploratory stage [1]. Up to now, the establishment of China's engineering education accreditation system and system has developed rapidly [2], and the relatively perfect evaluation system has almost achieved the equivalence of international accreditation [3]. China plans to achieve full coverage of all major categories by 2020, and build a three-level professional certification system. After a long time of supplement and improvement [4], China's professional certification standard has been relatively perfect, which is mainly composed of general standard and supplementary standard of engineering education professional certification [5]. General standards are interworking with international standards, covering all the standard items in international standards [6]. Professional supplementary standard is not a separate standard, but seven aspects of the general indicators are added to meet the special requirements of each specialty [7].

At present, half of all engineering disciplines in China have joined the evaluation and certification, and China is also committed to making all majors join the ranks of certification, which is also an important step to improve the certification system of Engineering Education in China [8]. Not only that, in the pursuit of "quantity", but also can not ignore "quality" [9]. In order to ensure that the certified majors can really cultivate professional talents with excellent comprehensive strength, we must ensure that the 
certification system is not only in line with international standards [10], but also in line with the actual situation of China. The reason is that although international mutual recognition is very important in the era of international integration in the future, serving our own country is the root Therefore [11], we can not ignore the Chinese characteristics in the formulation of the system [12].

Based on the design of general index, this paper will add Chinese characteristic index and complete the demand analysis of the system.

\section{Analysis on the Concept of General Standard}

The latest general standards of engineering education certification mainly include seven aspects: students, training objectives, graduation requirements, continuous improvement, curriculum system, teaching staff and supporting conditions [13]. The three concepts of engineering education accreditation are: student-centered, achievement oriented and continuous improvement [14]. Among them, student-centered is the purpose, achievement oriented is the requirement, and continuous improvement is the mechanism [15].

The connotation of the concept focuses on the cultivation of students [16]. The teaching content is designed according to the expectations of students. The evaluation object is the performance of students and the whole student must be considered [17]. The standard of measuring the teaching staff and other supporting conditions is whether it is conducive to students to achieve the expected goals. All conditions are intended to ensure that students can better complete the training objectives and achieve the graduation conditions.

The concept requires that the major that can be certified must prove that each qualified graduate achieves the goal and requirement through proof. The goal and graduation requirement must play a guiding role in daily teaching activities and help each person who undertakes the teaching task to clarify the responsibility. The evaluation of graduation requirements and training objectives must be decomposed into the whole process of students' learning.

The connotation of the concept is that the whole training process must be equipped with an effective quality monitoring and feedback mechanism. Teachers not only need to participate in the teaching plan design process, but also need to take responsibility in the monitoring and feedback mechanism. According to the students' performance feedback, they should continue to follow up, and adjust the training plan in time according to the feedback results. It is useless to only monitor the mechanism without improvement. In addition, in addition to the international common standards, the characteristic indicators also need to be added in the continuous feedback supervision mechanism.

\section{Evaluation Index Design}

According to the general standards of engineering education certification, interpretation of general standards for engineering education certification and relevant data analysis and design of the system certification indicators, classified into general indicators and characteristic indicators.

\subsection{General Standard Index Design}

The general standards are shown in Table 1 to table 7 . The specific connotation interpretation of the following indicators can be interpreted and used in accordance with the general standards for engineering education certification.

Table 1. Student indicators.

\begin{tabular}{ll}
\hline Index number & Index name \\
\hline TY1001 & Enrollment system and measures \\
TY1002 & Learning guidance \\
TY1003 & Follow up assessment of academic performance \\
TY1004 & Professional transfer regulations and credit recognition \\
\hline
\end{tabular}

Table 2. Training objectives.

\begin{tabular}{ll}
\hline Index number & Index name \\
\hline TY2001 & Training objectives and contents \\
TY2002 & Evaluation and revision of training objectives \\
\hline
\end{tabular}

Table 3. Graduation requirements.

\begin{tabular}{ll}
\hline Index number & Index name \\
\hline TY3001 & Engineering knowledge \\
TY3002 & problem analysis \\
TY3003 & Design / development solutions \\
TY3004 & Research \\
TY3005 & Using modern tools \\
TY3006 & Engineering and society \\
TY3007 & Environment and sustainable development \\
TY3008 & Professional norms \\
TY3009 & Individuals and teams \\
TY3010 & communicate \\
TY3011 & Communication project management \\
TY3012 & Lifelong learning \\
\hline
\end{tabular}

Table 4. Continuous improvement.

\begin{tabular}{ll}
\hline Index number & Index name \\
\hline TY4001 & Monitoring mechanism of teaching quality \\
TY4002 & Follow up feedback mechanism for graduates \\
TY4003 & Practicability of evaluation results \\
\hline
\end{tabular}

Table 5. Curriculum system.

\begin{tabular}{ll}
\hline Index number & Index name \\
\hline TY5001 & Mathematics and natural science courses \\
TY5002 & $\begin{array}{l}\text { Engineering and professional basic courses } \\
\text { TY5003 }\end{array}$ \\
PY500tice teaching system \\
Engineering practice and graduation project \\
TY5005 & General education courses of Humanities and Social \\
& Sciences \\
\hline Index number & Index name Teaching staff. \\
\hline TY6001 & Number of Teachers \\
TY6002 & Teachers' ability \\
TY6003 & Teaching work \\
TY6004 & Educational guidance \\
TY6005 & Education responsibility consciousness \\
\hline
\end{tabular}


Table 7. Support conditions.

\begin{tabular}{ll}
\hline Index number & Index name \\
\hline TY7001 & Classrooms, laboratories and equipment \\
TY7002 & Computer, network and library resources \\
TY7003 & Teaching funds \\
TY7004 & Construction of teaching staff \\
TY7005 & infrastructure \\
\hline
\end{tabular}

\subsection{Characteristic Index Design}

According to the relevant documents, the characteristic indexes other than the supplementary standards are shown in Table 8 to table 12 .

Table 8. Student characteristic index.

\begin{tabular}{ll}
\hline Index number & Index name \\
\hline TS1001 & Classified training \\
\hline
\end{tabular}

Explanation of index connotation: To focus on the classified cultivation of undergraduate talents, we should not only focus on the cultivation of high-level leading talents of engineering specialty, but also all levels and types of Engineering Science and technology talents.

Table 9. Training objectives and characteristic indicators.

\begin{tabular}{ll}
\hline Index number & Index name \\
\hline TS2001 & Training objectives aim at output \\
TS2002 & Moral cultivation \\
\hline
\end{tabular}

Explanation of index connotation:

TS2001: Design training system with advanced education concept. According to the school positioning, professional resources, social needs, stakeholder expectations and a series of conditions such as design and implementation, and the results of evaluation, continuous improvement.

TS2002: The training goal should not only focus on students' professional skills and working ability, but also on students' moral cultivation, so as to achieve both ability and political integrity, rather than "giant" in the industry and "villain" in the society.

Table 10. Characteristic index of graduation requirements.

\begin{tabular}{ll}
\hline Index number & Index name \\
\hline TS3001 & Match training objectives \\
\hline
\end{tabular}

Explanation of index connotation:

This standard requires that the graduation requirements must match with the training objectives to ensure the realization of the training objectives, so that the training objectives should not be gorgeous rhetoric, but the result of the joint efforts of teachers and students.

Table 11. Continuous improvement of characteristic indicators.

\begin{tabular}{ll}
\hline Index number & Index name \\
\hline TS4001 & Output oriented quality monitoring mechanism \\
\hline
\end{tabular}

Explanation of index connotation:

This standard requires that the quality monitoring mechanism should be output oriented, and the evaluation mechanism for the achievement of curriculum teaching objectives should be specific, specific, and clearly related to the graduation requirements. The evaluation results should be deeply analyzed, and the improvement scheme should be put forward based on the analysis results.

Table 12. Characteristic index of curriculum system.

\begin{tabular}{ll}
\hline Index number & Index name \\
\hline TS5001 & Supporting graduation requirements \\
TS5002 & Curriculum system layout \\
\hline
\end{tabular}

Explanation of index connotation:

TS5001: The curriculum system needs to ensure the achievement of the graduation requirement index points supported by it, decompose the graduation requirement achievement tasks into specific teaching activities, and the assessment (the evaluation of students' learning achievements) can reflect the substantial contribution to the achievement of the corresponding index points.

TS5002: The first connotation of this standard is that the curriculum system should have a "system", the overall layout is clear and reasonable, teachers should also participate in the design and formulation, master the design ideas of the curriculum system, and establish the overall view of talent training. It is necessary to satisfy the relationship between the leading and the following, adapt to the ability oriented education, and balance the distribution of curriculum components. And there are appropriate curriculum objectives, syllabus and so on.

\section{System Requirement Analysis}

\subsection{Feasibility Analysis}

Feasibility analysis is a multi-faceted analysis that should be carried out when contacting with a new project. It can determine whether the problem can be solved in the shortest possible time with the minimum cost. The results of the analysis are of great significance to the development of the project. In addition, we also need to consider the necessary cost of the development project, whether it can be successfully implemented in technology, and whether the user operation is difficult, etc. Only by integrating all the analysis can we finally decide whether the development of the system is feasible. As the system does not involve profit, the feasibility analysis is only from the technical feasibility and operational feasibility.

(1) The technical feasibility analysis needs to be based on the functions, performance and other constraints of the system, from the perspective of technical implementation, such as computer software, hardware, development environment, etc. The main functions of this system include submitting PDF files, viewing files, inputting evaluation results, algorithm operation, result feedback, user and application management, etc. This series of functions involve the connection of database. Mysql database is used in the database of this system, and idea is used in the programming software. The technical risk is low, and the required functions can be realized, and the 
performance, reliability and maintainability meet the requirements.

(2) Operation feasibility requires that all users including technicians can successfully complete a function in the process of operation after the completion of the system. The man-machine interaction page provided by the system is easy to understand, and the overall process is clear. The user needs to register, login, upload, click to view the evaluation results and other simple operations. Administrators need to delete, change and view user information and application information, and there is no difficulty in operation. The operation that evaluators need to do is to click to view the application, input the evaluation results in the evaluation page, which will provide 5 alternative evaluation results of all indicators, and then directly select the evaluation and finally submit it. To sum up, the system is feasible in operation.

\subsection{Functional Requirements}

This system is mainly divided into four modules. Next, the functional requirements of each module are introduced

User interaction module: the main function of this module is that users can register, log in, submit applications, and view evaluation results through this module. The specific process is to $\log$ in to the platform, upload all relevant information of the specialty to be applied, and these information will be recorded in the database. Experts can view these information and give evaluation results with the help of algorithm, and the results will be updated Feedback to the platform, users can view. This module uses the most basic registration login and file upload function, the key is to ensure the successful upload of data, because all the evaluation is based on the application data submitted by users, and the audit object of experts is also the data itself.

Evaluation module: This module specifies reasonable indexes according to the general evaluation standard of engineering education major. Experts can select the evaluation level of each index according to the relevant information provided by the major. The system will carry out certain calculation according to the selection result, and finally give the evaluation result suggestions and record the evaluation result. The core of the module is the process of evaluation, to ensure that all standard projects have selected the results, so as to ensure the data integrity in the data processing module.

Data processing module: This module converts the evaluation grade input by experts into computable data, and then calculates by certain algorithm according to different values and proportions. The final calculation results will be fed back to the system, and the data in this process will be recorded for query and change. The module focuses on the design of the algorithm, because the indicators are divided into two categories: general and characteristic, and the proportion of these two categories should be considered. Only when the algorithm is logical can the most accurate suggestions be given

Management module: the administrator of the system can $\log$ in to the management module for authorization, addition, deletion, modification and other behaviors. The administrator can't perform the evaluation task, but has the right to view, delete and modify the application, evaluation results and user information.

\subsection{Non Functional Requirements}

Non functional requirements include performance requirements, security requirements, maintainability and scalability requirements and reliability requirements.

Performance requirements: the performance of the system mainly includes response time and throughput. As the operation of the system only includes simple upload, submit and save, there should be no response timeout in response time. If there are too many authentication applications in a certain period of time, there may be stuck phenomenon. Because it involves the algorithm to calculate the data evaluation results and give the final recommendations, so the algorithm should choose the most efficient algorithm in the reasonable optimization at the same time, which can greatly improve the analysis efficiency of the system.

Security: the system will keep the user's personal information, submitted application information, evaluation results and other information strictly confidential, so as to prevent leakage and attack. The account authority will also be managed uniformly, and the security can be guaranteed

Maintainability and expansibility: with the gradual improvement of the whole evaluation system, the evaluation index, especially the characteristic index, will continue to increase. The system maintains good expansibility, the index can be changed at any time, and the system will regularly sort out and maintain the account information.

Reliability: in terms of reliability, the system requires that it can be provided to experts in time after receiving user messages, and ensure that different applications can be carried out in parallel accurately at the same time, and ensure that the platform can run effectively on hardware with high pressure resistance, so as to ensure the successful evaluation process of each application in the peak period of centralized application.

\section{Conclusion}

Engineering education professional certification in China from the emergence to the present steady development, after years of improvement, has formed a more reasonable system, and has completed hundreds of professional certification process. Today, engineering education is very important, and the importance of engineering education professional certification is more and more prominent. The certification and affirmation of a major, to a certain extent, ensure the quality of personnel training. This paper has done the analysis of related theory and technology, analysis and design of certification index, system analysis and so on. It is worth noting that in order to make the system more suitable for China's engineering education, in addition to the general indicators, the characteristic indicators with Chinese characteristics are extracted, and these indicators are classified separately. In the future, the system will give the 
recommended ratings of the general indicators and characteristic indicators according to the specific algorithm, which can ensure that the system can be in line with international standards without losing its own characteristics It is not only limited to application, evaluation and feedback, but also involves on-the-spot inspection, which needs to rely on manual further evaluation. Therefore, the system can not directly give the final certification results, but only provides a platform between the school and experts in the evaluation of application.

\section{Acknowledgements}

My thesis would like to thank the course construction project (040000513125) of School of software, Faculty of information Technology, Beijing University of technology for its financial support. In the process of our research, the required experimental and testing environment is also provided by the college. At the same time, I would also like to thank the authors of references and related researchers. Their research has given me important reference and help, and provided a good reference for the completion of my thesis.

\section{References}

[1] Yanhong Bai, Research and Practices on Formative Assessment of Curriculum Objectives under the Background of Engineering Education Accreditation. China Higher Education Research, Vol 12, 2019, pp. 60-64.

[2] Yingguo Zhou, Xiaomei Sun, Construction of quality evaluation system for talent cultivation in Higher Engineering Education. University Education, Vol 5, 2019, pp. 144-147.

[3] Dexin $\mathrm{Hu}$, The comparison and reference of international reform of engineering education professional accreditation system under the background of the new industrial revolution. Journal of Higher Education Management, Vol 5, 2019, pp. $72-81$.

[4] Hao Wang, Xinqin Gao, On the implementation strategy of engineering education professional certification. Higher Education Forum, Vol 2, 2019, pp. 81-83.

[5] Chenyu Shi, An Exploration of Undergraduate Program Design in the Background of China Engineering Education Accreditation. Future and Development, Vol 6, 2019, pp. 59-61.
[6] Zenlin Zhang, Thoughts on the professional certification of Higher Engineering Education in Local Universities. Journal of Hubei Engineering University, Vol 4, 2019, pp. 44-48.

[7] Ying Xiong, Yawu Me, Yang Xiang, Professional Certification of Engineering Education Promotes the Reform of Engineering Practice Teaching in Colleges and Universities. The Guide of Science \& Education, Vol 33, 2019, pp 56-57.

[8] Xiaojing Li, Xiao Yu, Yajuan Gao, Discussion on Engineering Teaching under the background of Engineering Education Accreditation. Education and Cultivation, Vol 4, 2019, pp. 74-75.

[9] Wei Chen, The Relationship Between Innovation Ability Training and Engineering Education Specialty Certification. jiaoyu jiaoxue luntan, Vol 9, 2020, pp. 143-144.

[10] Lei Du, Huagang He, Wei Wang, Thoughts on the Status of the Engineering Education Professional Certification Work in Mainland China. jiaoyu jiaoxue luntan, Vol 7, 2020, pp. 339-341.

[11] Xinqin Gao, Xin Lu, Hao Wang, Taking engineering education certification as the starting point to promote the construction of "first class specialty". University Education, Vol 11, 2020, pp. 63-66.

[12] Ouxu Ren, Zhanpeng Sun, Exploration on talent training scheme of Engineering Education under the background of professional certification. Contemporary Education Research and Teaching Practice, Vol 17, 2020, pp. 354-355.

[13] Hui $\mathrm{Li}$, On engineering education accreditation and engineering education reform in Local Universities. Modern Vocational Education, Vol 23, 2020, pp. 198-199

[14] Ting Cai, Yuxin Wu, Research on the construction of software engineering curriculum cluster driven by engineering education certification. The Chinese Journal of Ict in Education, Vol 2, 2020, pp. 46-49.

[15] Qilin Zhang, Yongbiao Zhao, Dongsheng Xiang, Integration path of curriculum ideological and political education and engineering education professional certification. Computer Education, Vol 3, 2021, pp. 76-80.

[16] Yang Liu, Xia Tian, Research on professional practice teaching standards from the perspective of engineering education professional certification. University Education, Vol 3, 2021, pp. 11-15.

[17] Fei Wang, Shenghui Liu, Yuxiang Cui, On the construction of new engineering courses in Local Engineering Colleges under the background of Engineering Education Accreditation. Journal of Higher Education, Vol 3, 2021, pp. 63-66. 